www.jmscr.igmpublication.org

Index Copernicus Value: 79.54

ISSN (e)-2347-176x ISSN (p) 2455-0450

crossref DOI: https://dx.doi.org/10.18535/jmscr/v7i4.177

\title{
Yolk sac size and embryonic heart rate as prognostic factors of first trimester pregnancy outcome
}

\author{
Author
}

\section{Dr Sapna Aseri}

MS (Obst \& gynae), Senior Resident, Department of Obs \& Gynaecology

RVRS Medical College \& Attached groups of Mahatma Gandhi Hospital, Bhilwara, Raj, India

\begin{abstract}
Background: Many studies on the prognostic significance of the Yolk sac for the pregnancy outcome have been performed with conventional sonography and more recently with TVS. The results are conflicting. This prospective co relational study is conducted to assess the correlation of first trimester pregnancy outcome using yolk sac measurements and embryonic heart rate.

Material \& Methods: A Hospital based prospective study done on 100 pregnant women between 6-9 weeks of gestation who were attending the antenatal clinic in Department of Obstetrics and Gynaecology, Mahatma Gandhi Hospital, Bhilwara, Rajasthan. Follow up scan: was done every two weeks where (gestational sac diameter, yolk sac diameter, crown rump length and fetal heart rate) were measured every time until the pregnancy reached 12 weeks.

Results: The Yolk sac size varied between 2.5 to 7.0 with a mean of $4.892 \mathrm{~mm}$. The Yolk sac size has significant correlation with the first trimester pregnancy outcome. ( $T$-test $p=0.002 * *)$. The heart rate of the fetus predicted the first trimester pregnancy outcome significantly (T-test $\left.p=0.048^{*}\right)$.

The gestational Age at the time of first scan predicted very significantly the first trimester pregnancy outcome (T-test $\left.p<0.001^{* *}\right)$. The Crown Rump Length $(C R L)$ was ranged between 10 and $58 \mathrm{~mm}$ with a mean of $24.51 \mathrm{~mm}$. The CRL has significant predictive value in first trimester pregnancy outcome (T-test $p=0.044 *)$.

Conclusion: We concluded that yolk sac size and the embryonic heart rate is a reliable, cost effective and beneficial in predicting first trimester pregnancy outcome especially in patients who conceive following IVF.

Keywords: First trimester pregnancy, Yolk sac size, Crown rump length, Gestational age, Heart rate.
\end{abstract}

\section{Introduction}

Spontaneous abortions or early pregnancy failure is one of the most frequent complications of pregnancy, but great difficulty is still experienced in reliably anticipating which pregnancies will terminate in abortion. This situation is particularly distressing to those patients with history of threatened or recurrent abortion who abort despite resting in the hospital for many weeks. ${ }^{1}$ Therefore there is a need for techniques which will allow early diagnosis to be made in these patients, preferably with such certainty that a more active line of management can be pursued if so desired. The secondary yolk sac is the first extraembryonic structure that can be detected with transvaginal sonography (TVS) in the chorionic cavity and can be seen from the $5^{\text {th }}$ to the $12^{\text {th }}$ week menstrual age, at the latest. During organogenesis and before 
placental circulation is established, yolk sac is the primary source of exchange between the embryo and the mother. ${ }^{2}$ Yolk sac has nutritive, endocrine, metabolic, immunologic, secretory, excretory and hematopoietic functions. Many studies on the prognostic significance of the Yolk sac for the pregnancy outcome have been performed with conventional sonography and more recently with TVS. The results are conflicting. Ultrasound is the primary imaging modality in obstetrics over the last three decades. The advent of high-resolution transvaginal ultrasound (TVS) has revolutionized our understanding of the pathophysiology and the management of early pregnancy failure. Knowledge of the ultrasound appearances of normal early pregnancy development and a good understanding of its pitfalls are essential for the diagnosis and management of early pregnancy failure. ${ }^{3}$ Ultrasound imaging has rapidly replaced all other techniques used to study normal human development in the first trimester, and ultrasound features of the early gestational sac have corroborated anatomical studies showing that the first structures to appear are the coelomic cavity and the secondary yolk sac. ${ }^{4}$ No single ultrasound measurement of the different anatomical features in the first trimester has been shown to have a high predictive value for determining early pregnancy outcome. This prospective co relational study is conducted to assess the correlation of first trimester pregnancy outcome using yolk sac measurements and embryonic heart rate.

\section{Material \& Methods}

A Hospital based prospective study done on 100 pregnant women between 6-9 weeks of gestation who were attending the antenatal clinic in Department of Obstetrics and Gynaecology, Mahatma Gandhi Hospital, Bhilwara, Rajasthan

\section{Selection Criteria \\ Inclusion Criteria}

- Pregnant women at menstrual age less than 10 weeks

- Antenatal patients with single gestation and live embryo
- Age $<30 y r s$

\section{Exclusion Criteria}

1. Molar pregnancy

2. Women with structural anomalies of uterus and cervix

3. Women with known endocrine disorder causing abnormal pregnancy outcome.

4. Pregnancy from infertility treatment

5. Cases without embryonic heart rate, anembryonic pregnancy, subchorionic haemorrhage and inconsistency between gestational sac size and CRL.

6. Women who has used any abortive or teratogenic drugs

\section{Methods}

Women attending routine antenatal check up in the out-patient department were subjected to scan. Only those antenatal women who have $<30$ years and of singleton pregnancy were included in the study.

A detailed history was elicited with special reference to the last menstrual period, its regularity and other associated risk factors like diabetes mellitus, hypertension, hypothyroidism, cardiac disease and bronchial asthma. Then a thorough general, physical, systematic and obstetric examination was carried out. After obtaining informed consent the women between less than 10 weeks of gestation were subjected to transvaginal ultrasound.

A first ultrasound scan: between 5 and 6 weeks of gestation according to their first antenatal care visit that included the following:

- Gestational sacs,

- The yolk sac diameter (YSD),

- Crow- rump length (CRL) measurement,

- Fetal heart rate measurements.

Follow up scan: was done every two weeks where (gestational sac diameter, yolk sac diameter, crown rump length and fetal heart rate) were measured every time until the pregnancy reached 12 weeks. 


\section{Statistical analysis}

Descriptive analysis was done to find the mean and standard deviation. Analysis of variance (ANOVA) was performed to compare various groups. A "p" value of 0.005 or less considered as statistically significant.

\section{Results}

Age at the time of pregnancy and first Sonogram correlates with the first trimester pregnancy outcome (One way ANOVA $\mathrm{p}=0.028^{*}$ ). Mean age was 23.73 years with minimum 16 years and maximum of 36 years.

The Yolk sac size varied between 2.5 to 7.0 with a mean of $4.892 \mathrm{~mm}$. The Yolk sac size has significant correlation with the first trimester pregnancy outcome. (T-test $\left.\mathrm{p}=0.002^{* *}\right)$. The heart rate of the fetus ranged between 100 and 180, with a mean of 154.62. The heart rate of the fetus predicted the first trimester pregnancy outcome significantly ( $T$-test $\left.\mathrm{p}=0.048^{*}\right)$.

The gestational Age at the time of first scan predicted very significantly the first trimester pregnancy outcome (T-test $\mathrm{p}<0.001 * *)$ Gestational age ranged between 6.0 to 11.5 weeks with a mean of 8.426 weeks. The Crown Rump Length (CRL) was ranged between 10 and $58 \mathrm{~mm}$ with a mean of $24.51 \mathrm{~mm}$. The CRL has significant predictive value in first trimester pregnancy outcome $(T$-test $\mathrm{p}=0.044 *)$.

Table 1: Descriptive data of all cases

\begin{tabular}{|l|c|c|c|}
\hline Data & Minimum & Maximum & Mean \\
\hline Age (years) & 16 & 36 & 23.73 \\
\hline Married since (years) & 0.3 & 7.0 & 2.062 \\
\hline Gestational Sac Size (mm) & 12 & 67 & 32.12 \\
\hline Yolk sac size (mm) & 2.5 & 7.0 & 4.892 \\
\hline Heart Rate (Bpm) & 100 & 180 & 154.62 \\
\hline Gestational Age (weeks) & 6.0 & 11.5 & 8.426 \\
\hline Crown Rump Length (mm) & 10 & 58 & 24.51 \\
\hline
\end{tabular}

Table 2: Age and Pregnancy outcome

\begin{tabular}{|c|c|c|c|c|c|}
\hline & & & & Std. Error Mean \\
\hline \multirow{2}{*}{ Age in years } & Pregnancy outcome & $\mathrm{N}$ & Mean & Std. Deviation & \\
\cline { 2 - 6 } & Miscarriage & 18 & 23.41 & 3.697 & 0.366 \\
\hline
\end{tabular}

\section{Independent Samples Test}

\begin{tabular}{|c|c|c|c|c|c|c|}
\hline & \multicolumn{6}{|c|}{ t-test for Equality of Means } \\
\hline & \multirow[t]{2}{*}{$\mathrm{t}$} & \multirow[t]{2}{*}{ df } & \multirow[t]{2}{*}{ Sig. (2-tailed) } & \multirow[t]{2}{*}{$\begin{array}{c}\text { Mean } \\
\text { Difference }\end{array}$} & \multicolumn{2}{|c|}{$\begin{array}{l}\text { 95\% Confidence Interval of the } \\
\text { Difference }\end{array}$} \\
\hline & & & & & Lower & Upper \\
\hline \multirow[t]{2}{*}{ Age in years } & -2.230 & 118 & 0.028* & -2.09 & -3.943 & -0.234 \\
\hline & -2.341 & 24.415 & 0.028 & -2.09 & -3.928 & -0.249 \\
\hline
\end{tabular}

Table 3: Yolk sac Size and Pregnancy outcome

\begin{tabular}{|c|c|c|c|c|c|}
\hline & Pregnancy outcome & $\mathrm{N}$ & Mean & Std. Deviation & td. Error Mean \\
\hline \multirow{2}{*}{ Yolk sac $(\mathrm{mm})$} & Normal & 102 & 4.804 & 0.7304 & 0.0723 \\
\cline { 2 - 6 } & Miscarriage & 18 & 5.389 & 0.6764 & 0.1594 \\
\hline
\end{tabular}




\begin{tabular}{|c|c|c|c|c|c|c|}
\hline & \multicolumn{6}{|c|}{ t-test for Equality of Means } \\
\hline & \multirow[b]{2}{*}{$\mathrm{t}$} & \multirow[b]{2}{*}{ df } & \multirow[b]{2}{*}{ Sig. (2-tailed) } & \multirow{2}{*}{$\begin{array}{c}\text { Mean } \\
\text { Difference }\end{array}$} & \multicolumn{2}{|c|}{ Confidence Interval of the Difference } \\
\hline & & & & & Lower & Upper \\
\hline \multirow[t]{2}{*}{ Yolk sac (mm) } & -3.165 & 118 & $0.002 * *$ & -0.585 & -0.9509 & -0.2190 \\
\hline & -3.341 & 24.541 & 0.003 & -0.585 & -0.9459 & -0.2241 \\
\hline
\end{tabular}

Table 4: Embryonic heart rate and pregnancy outcome

\begin{tabular}{|l|c|c|c|c|c|}
\hline & & & & Std. Error Mean \\
\hline $\begin{array}{l}\text { Embryonic } \\
\text { Rate (bpm) }\end{array}$ & Preartancy outcome & $\mathrm{N}$ & Mean & Std. Deviation & \\
\cline { 2 - 6 } & Normal & 102 & 155.88 & 14.298 & 1.416 \\
\hline
\end{tabular}

\begin{tabular}{|l|c|c|c|c|c|c|}
\hline & \multicolumn{2}{|c|}{} & \multicolumn{4}{|c|}{ t-test for Equality of Means } \\
\cline { 2 - 7 } & $\mathrm{t}$ & $\mathrm{df}$ & $\begin{array}{r}\text { Sig. (2- } \\
\text { tailed) }\end{array}$ & $\begin{array}{r}\text { Mean } \\
\text { Difference }\end{array}$ & \multicolumn{2}{|c|}{$\begin{array}{c}\text { 95\% Confidence Interval of the } \\
\text { Difference }\end{array}$} \\
\cline { 5 - 7 } & 1.994 & 118 & $\mathbf{0 . 0 4 8}^{*}$ & 8.44 & 0.059 & Upper \\
\hline $\begin{array}{l}\text { Embryonic } \\
\text { Heart Rate } \\
\text { (bpm) }\end{array}$ & 1.332 & 18.825 & 0.199 & 8.44 & -4.833 & 16.817 \\
\hline
\end{tabular}

Table 5: Correlation of Pregnancy outcome with all other parameters (AFTER EXCLUDING THE CASES WITH UNKNOWN 'LMP')

One Way ANOVA with Post HOC Turkey test

\section{ANOVA}

\begin{tabular}{|ll|c|c|c|c|c|}
\hline & & Sum of Squares & df & Mean Square & F & Sig. \\
\hline Gestational & Between Groups & 515.222 & 1 & 515.222 & 6.792 & $\mathbf{0 . 0 1 0}$ \\
& & & & & & \\
& Within Groups & 8040.518 & 106 & 75.854 & & \\
& Total & 8555.741 & 107 & & & \\
\hline Yolk sac size & Between Groups & 7.507 & 1 & 7.507 & 16.886 & $\mathbf{0 . 0 0 0 * *}$ \\
& Within Groups & 47.123 & 106 & .445 & & \\
& Total & 54.629 & 107 & & & \\
\hline Embryonic & Between Groups & 1069.914 & 1 & 1069.914 & 3.763 & $\mathbf{0 . 0 5 5 ^ { * }}$ \\
heart rate & Within Groups & 30140.271 & 106 & 284.342 & & \\
& Total & 31210.185 & 107 & & & \\
\hline Gestational & Between Groups & 23.553 & 1 & 23.553 & 18.119 & $\mathbf{0 . 0 0 0 * *}$ \\
age & & 137.791 & 106 & & & \\
& Within Groups & 161.343 & 107 & & & \\
\hline Cotal & Between Groups & 196.721 & 1 & 196.721 & 3.257 & 0.074 \\
& Within Groups & 6401.529 & 106 & 60.392 & & \\
\hline Total & 6598.250 & 107 & & & \\
\hline
\end{tabular}

\section{Discussion}

Miscarriage occurs in approximately $30-40 \%$ of implanted pregnancies, is the commonest complication of pregnancy. ${ }^{5}$ Numerous studies have examined the potential value of demographic characteristics and various ultrasonographic parameters in the prediction of those pregnancies that will miscarry.

Our study supports the fact that as the maternal age increases, chances of spontaneous abortion 
also increases. Studies have also shown that the rate of spontaneous abortion following cardiac activity is influenced by maternal age. So a cardiac activity is not necessarily a reassuring sign in the older patient. ${ }^{6}$ Our study is in agreement with the fact that consanguinous marriage increases the adverse outcome. Consanguinous marriage is still prevalent in the population studied.

In our study Gestational sac mean size was 32.12 and significantly correlates with the first trimester outcome $(\mathrm{p}=0.007 * *)$. It was $33.10 \mathrm{~mm}$ mean in the normal pregnancies and mean of $26.61 \mathrm{~mm}$ in miscarriage group. It has long been recognized that there is wide scatter in gestational sac volume measurements in 'normal' early pregnancy. ${ }^{7} \mathrm{~A}$ smaller than expected gestational sac can be a predictor of poor pregnancy outcome, both alone and in combination with other parameters, even in the presence of embryonic cardiac activity, In very early pregnancy, there appears to be no difference in gestational sac diameter (GSD) when compared with pregnancy outcome, the difference only becoming apparent from 5 weeks onwards. ${ }^{8}$ Once a gestational sac has been documented on ultrasound, subsequent loss of viability in the embryonic period remains around $11 \% .^{9}$ So, Gestational sac size measurements could not be considered as good predictor of first trimester outcome even though it had significant correlation in our study.

The increase in yolk sac diameter during the first trimester and its correlation with advancing gestational age lie in agreement with most of the previous studies ${ }^{10}$, although some researchers support that the growth of yolk sac during the first trimester is not constant. ${ }^{11} \mathrm{We}$ demonstrated that the pregnancies with mean yolk sac diameter >or $=5 \mathrm{~mm}$ on early ultrasound require monitoring and counseling. About a threefold increased risk for first-trimester loss independent of maternal risk factors such as age, body mass index, polycystic ovary syndrome, smoking, and diabetes and we agree with recent studies that support the negative predictive value of the absence of yolk sac. ${ }^{12,13}$ We studied only the yolk sac size and not its shape; therefore we cannot comment on previous articles that associate abnormal shapes of the yolk sac with poor pregnancy outcome. ${ }^{14}$ In addition, enlarged yolk sac diameter may be associated with an increased risk of preterm delivery. ${ }^{15}$

Embryonic heart rate has significant correlation with the first trimester outcome in our study $(\mathrm{p}=0.048 *)$. FHR has been studied extensively and numerous studies have demonstrated a strong association between pathological FHR and fetal loss. Fetal bradycardia is a sign of impending fetal death reflecting the forthcoming collapse of the cardiovascular system. Another possible cause for the high miscarriage rate in fetuses with abnormal FHR is that there may be an underlying chromosomal abnormality, such as trisomy 18 or triploidy, which is associated with fetal bradycardia. $^{16}$ But tachycardia is a feature of trisomy 21(Down Syndrome). ${ }^{17}$

The ultrasonographic estimation of gestational age in our study has significant correlation with pregnancy outcome $\left(\mathrm{p}<0.001^{* *}\right)$. The inverse relationship between gestational age and fetal loss rate is consistent with the results of previous studies and may also be a consequence of the high early lethality of chromosomally abnormal embryos. ${ }^{18}$ For example, a previous study of 6337 pregnancies reported an inverse correlation between gestation and rate of subsequent fetal loss, which decreased by about $1 \%$ per week from $9.6 \%$ at 7 weeks to 2.3 at 14 weeks. ${ }^{19}$

In fetuses with CRL $<18 \mathrm{~mm}$ there was a significant positive association between the deficit in CRL for gestation and the incidence of subsequent spontaneous miscarriage. ${ }^{20}$ In our study Crown rump length inversely associated with miscarriage $\left(\mathrm{p}=0.044^{*}\right)$. CRL is $\angle 22 \mathrm{~mm}$ in miscarriages in our study, this correlation stands with most of the previous studies. The measurement of fetal CRL may be a useful predictor of spontaneous miscarriage and SGA in pregnancies with threatened miscarriage.

The limitation of ultrasound examination depends 
on the machine type, operator factors and timing of scan and our study also has limitation of low volume. In spite of all these limitations we postulate that measurement of yolk sac size and embryonic heart rate in early pregnancy may predict the first trimester outcome and plan for timing of follow up; also to counsel the patient about the short term and long term outcomes.

\section{Conclusion}

We concluded that yolk sac size and the embryonic heart rate is a reliable, cost effective and beneficial in predicting first trimester pregnancy outcome especially in patients who conceive following IVF.

\section{References}

1. Siddiqi TA, Caligaris JT, Miodovnik M et $a l .:$ Rate of spontaneous abortion after first trimester sonographic demonstration of fetal cardiac activity. Am. J. Perinatol.1988; 5(1): 1-4.

2. Berdahl DM, Blaine J, Van Voorhis B et $a l .:$ Detection of enlarged yolk sac on early ultrasound is associated with adverse pregnancy outcomes. Fertil. Steril.,2010; 94:1535-1537.

3. Kaur A and Kaur A: Transvaginal ultrasonography in first trimester of pregnancy and its comparison with transabdominal ultrasonography. J.Pharm. Bioallied. Sci.,2011; 3(3): 329-338.

4. Lyons EA and Levi CS: The first trimester. In: Diagnostic Ultrasound. Rumack CM, Wilson SR, Charboneau JW (eds).3rd ed. Mosby Co.London.pp: 2005; 1070-1100.

5. Knudsen UB, Hansen V, Juul S, Secher NJ. Prognosis of a new pregnancy following previous spontaneous abortions. Eur J Obstet Gynecol Reprod Biol 1991;39:31-6.

6. Smith, K.E. and Buyalos, R.P. The profound impact of patient age on pregnancy outcome after early detection of fetal cardiac activity. Fertil.Steril.,1996; $65,35-40$.

7. 'Gestational sac' volumes as determined by sonar in the first trimester of pregnancy, Robinson HP. $\mathrm{Br} J$ Obstet Gynaecol 1975; 82: 100-107.

8. Gestational sac diameter in very early pregnancy as a predictor of fetal outcome. Oh JS, Wright G, Coulam CB. Ultrasound Obstet Gynecol 2002; 20: 267.

9. Goldstein SR.Embryonic death in early pregnancy: a new look at the first trimester., Obstet Gynecol 1994; 84: 294 297.

10. Cepni I, Bese T, Ocal P, Budak E, Idil M, Aksu MF. Significance of yolk sac measurements with vaginal sonography in the first trimester in the prediction of pregnancy outcome. Acta Obstet Gynecol Scand 1997;76: 969-72.

11. Blaas HG, Eik-Nes SH, Bremnes JB. The growth of the human embryo. A longitudinal biometric assessment from 7 to 12 weeks of gestation. Ultrasound Obstet Gynecol 1998;12:346-54.

12. Schouwink MH, Fong BF, Mol BW, van der Veen F. Ultrasonographic criteria for non-viability of first trimester intra-uterine pregnancy.. Early Pregnancy 2000;4:20313.

13. Stampone C, Nicotra M, Muttinelli C, Cosmi EV. Transvaginal sonography of the yolk sac in normal and abnormal pregnancy. J Clin Ultrasound 1996;24:3-9.

14. Kucuk T, Duru NK, Yenen MC, Dede M, Ergun A, Baser I. Yolk sac size and shape as predictors of poor pregnancy outcome. $\mathbf{J}$ Perinat Med 1999;27:316-20.

15. Berdahl DM, Blaine J, Van Voorhis B, Dokras A. Detection of enlarged yolk sac on early ultrasound is associated with adverse pregnancy outcomes. Fertil Steril. 2010 Sep; 94(4):1535-7. Epub 2010 Feb 13.

16. Liao AW, Snijders R, Geerts L, Spencer 
K, Nicolaides KH. Fetal heart rate in chromosomally abnormal fetuses. Ultrasound Obstet Gynecol 2000; 16: 610-613.

17. Jauniaux, E., Gavrill, P., Khun, P. et al. Fetal heart rate and umbilicoplacental Doppler flow velocity waveforms in early pregnancies with a chromosomal abnormality and/or an increased nuchal translucency thickness. Hum. Reprod. 1996; 11, 435-439.

18. Snijders RJ, Sebire NJ, Nicolaides KH. Maternal and gestational age specific risk for chromosomal defects. Fetal Diagn Ther 1995; 10: 356-367.

19. Gustavii B. Chorionic biopsy and miscarriage Lanc et 1984; 1:562.

20. Reljic M. The significance of crown-rump length measurement for predicting adverse pregnancy outcome of threatened abortion. Ultrasound Obstet Gynecol. 2001 Jun;17(6):510-2. 